\title{
Response Estimation of Wheat Synthetic Lines to Terminal Heat Stress Using Stress Indices
}

\author{
S. Sareen ${ }^{1}$, B. S. Tyagi ${ }^{1}$, V. Tiwari ${ }^{1} \&$ I. Sharma ${ }^{1}$ \\ ${ }^{1}$ Directorate of Wheat Research, Karnal (Haryana), India \\ Correspondence: S. Sareen, Directorate of Wheat Research, PO Box 158, Karnal 132001 (Haryana), India. Tel: \\ 91-184-226-7830. E-mail: sareen9@hotmail.com
}

Received: June 4, 2012 Accepted: June 19, 2012 Online Published: August 24, 2012

doi:10.5539/jas.v4n10p97

URL: http://dx.doi.org/10.5539/jas.v4n10p97

\begin{abstract}
Twenty eight synthetic wheat lines were evaluated for terminal heat tolerance by normal (non-stress) and late (stress) planting in field in randomized block design with three replications for two crop seasons; 2008-09 and 2009-10. The genotypes differed significantly for thousand grain weight in non-stress and stress conditions. The stress susceptibility and tolerance indices were calculated for thousand grain weight and genotypes differed significantly for stress indices also. The stress tolerance indices; Stress tolerance index, Geometric mean production and Mean production had significant positive correlation with thousand grain weight in non-stress and stress conditions. The first two principal components explained more than 89 and $98 \%$ of variation during two crop seasons respectively. The study using bilpot analysis revealed that stress tolerance indices can be selection criteria for identification of tolerant genotypes. Using three dimensional plot, the genotypes which performed well in both environments or in one of the environments only or in none of the environments were identified. The synthetic wheat lines S9, S37, S44 and S57 had high thousand grain weight with heat tolerance during both years and genotypes S8, S22, S23, S49 and S77 had poor performance in both environments.
\end{abstract}

Keywords: bi-plot, principal component analysis, stress indices, synthetic wheat lines, three dimensional plot

Abbreviations: SSI-Stress susceptibility index, TOL-Stress tolerance, MP-mean production, GMP-geometric mean production, STI-Stress tolerance index, TGW-Thousand grain weight

\section{Introduction}

Wheat (Triticum aestivum), a climate sensitive crop, is presently grown on 29 mha in India and about 13.5 mha of this area faces thermal stress, resulting either from supra-optimal or sub-optimal temperatures. A significant wheat growing area in South Asia is affected by heat stress and majority of this area lies in Eastern Gangetic Plains, central and peninsular parts of India (Joshi et al., 2007a, b). Globally, wheat on 36 Mha area ( $40 \%$ of the temperate environment) is subjected to heat (terminal heat in irrigated environments) stress (Hays et al., 2007; Reynolds et al., 2001). It is predicted that increase of $1{ }^{\circ} \mathrm{C}$ in temperature will result in 4-5 million tons (3-4\%) of loss in wheat production (Wardlaw et al., 1989). Likewise, the heat stress resulting from delay in sowing by one month can lead to about $20-30 \%$ loss in grain yield depending on climatic conditions. In order to meet the challenging temperature ahead of global warming, there is need to incorporate heat tolerance into wheat germplasm and develop genotypes which are suitable to such stressed environments. Various stress susceptibility indices like TOL and SSI and stress tolerance indices like GMP, MP and STI have been proposed by various researchers (Fischer \& Maurere, 1978; Rosielle \& Hamblin, 1981; Fernandez, 1992). Whereas the susceptibility indices differentiate the tolerant and susceptible genotypes, the tolerance indices particularly STI differentiate the genotypes with stress tolerance and yield potential. The synthetic hexaploids have been derived from crossing between tetraploid durum wheat with diploid T. tauschii (D genome). The primary synthetic hexaploids are agronomically poor, late flowering, hard threshing, generally tall, low yielding with red grains, but also source for desirable traits like resistance/tolerance to biotic and abiotic stresses. Ninety synthetic wheat lines were procured from CIMMYT and were preliminary screened under polyhouse conditions for two consecutive years. The heat tolerant and susceptible synthetic lines selected from this preliminary study were evaluated under field conditions for two consecutive years to identify lines, which bear heat tolerance as well as reasonable thousand grain weight. Such lines can be used in breeding programme targeted for heat stressed environments. 


\section{Materials and Methods}

\subsection{Site of Experiments}

The experiments were conducted at Research farm of Directorate of Wheat Research, Karnal, (Latitude $29^{\circ} 43^{\prime} \mathrm{N}$, Longitude 76 $48^{\prime} \mathrm{E}$, altitude, $245 \mathrm{~m}$ ) during 2008-09 and 2009-10 crop seasons.

\subsection{Experimental Material and Heat Stress Treatments}

The experimental material consisted of 28 synthetic wheat lines. Pedigree details of these synthetic wheats are given in Table 1. These synthetic wheat lines were evaluated for two consecutive crop seasons and two conditions; non-stress (timely November sowing) and stress (late December sowing) using RCBD with three replications. The plot size was $2.4 \mathrm{~m}^{-2}$ with 4 rows of $2 \mathrm{~m}$ length and $0.3 \mathrm{~m}$ spacing. Fertilizer and irrigation were applied as per recommendations. Data was recorded for thousand grain weight.

Table 1. Pedigree of synthetic wheats used in present study

\begin{tabular}{|c|c|}
\hline Genotype & Pedigree \\
\hline S8 & CPI/GEDIZ/3/GOO//JO69/CRA/4/Ae.squarrosa(208) \\
\hline S9 & ALTAR 84/ Ae.squarrosa(192) \\
\hline S11 & D67.2/P66.270//Ae. squarrosa(213) \\
\hline S14 & YUK/Ae.squarrosa (217) \\
\hline S16 & ALTAR 84/ Ae.squarrosa (219) \\
\hline S18 & D67.2/P66.270//Ae. squarrosa(220) \\
\hline S22 & D67.2/P66.270//Ae. squarrosa(222) \\
\hline S23 & D67.2/P66.270//Ae. squarrosa(223) \\
\hline S24 & CROC_1/Ae.squarrosa (224) \\
\hline S27 & GARZA/BOY//Ae.squarrosa (311) \\
\hline S28 & $69.111 /$ RGB-U//WARD/3/Ae.squarrosa $(316)$ \\
\hline $\mathrm{S} 31$ & 68112/WARD//Ae.squarrosa(369) \\
\hline S34 & DOY 1/Ae.squarrosa (511) \\
\hline S35 & $68.111 /$ RGB-U/ iWARD/3/Aesquarrosa (511) \\
\hline S36 & DOY 1/Ae.squarrosa( (515) \\
\hline S37 & 68.111/RGB-U//WARD/3/ FGO/4/RABI/5/Ae.squarrosa(629) \\
\hline S38 & FGO/USA2111//Ae.squarrosa(658) \\
\hline S42 & YAR/Ae.squarrosa (783) \\
\hline S44 & 68.111/RGB-U//WARD/3/ FGO/4/RABI/5/ Ae. squarrosa(878) \\
\hline S46 & CROC_1/Ae.squarrosa $(879)$ \\
\hline S49 & 68.111/RGB-U//WARD/3/ FGO/4/RABI/5/ Ae. squarrosa(890) \\
\hline S51 & PBW114/Ae. squarrosa \\
\hline S52 & ALTAR 84/Ae.squarrosa (JBANGOR) \\
\hline S57 & LC,K59. 6'1/Ae.squarrosa(313) \\
\hline S67 & SNIPE/YAV79//DACK/TEAL/3/Ae.squarrosa (629) \\
\hline S71 & TRN/Ae. squarrosa $(700)$ \\
\hline S76 & FALCIN/Ae.squarrosa $(312)$ \\
\hline S77 & RASCON/Ae.squarrosa(312) \\
\hline
\end{tabular}

Daily mean maximum and mean minimum temperatures were recorded for characterization of environments. The temperature data for both years are given in Table 2. Mean minimum and maximum temperatures before 
and after heading were calculated by taking into consideration the minimum number of days to heading and maximum number of days to maturity (Table 3 ).

Table 2. Average maximum and minimum temperature during pre heading and post heading periods under timely and late sown conditions during two seasons

\begin{tabular}{lccccccccc}
\hline & \multicolumn{3}{c}{$2008-09$} & \multicolumn{2}{c}{$2009-10$} & \multicolumn{3}{c}{$2008-09$} & \multicolumn{2}{c}{$2009-10$} \\
\hline & \multicolumn{4}{c}{ Pre heading } & \multicolumn{4}{c}{ Post heading } \\
\hline Max & Min & Max & Min & Max & Min & Max & Min \\
\hline Timely (Non stress) & 21.7 & 8.5 & 20.2 & 6.9 & 30.8 & 14.2 & 31.0 & 14.1 \\
Late (Stress) & 22.2 & 8.9 & 19.8 & 7.4 & 32.1 & 13.8 & 35.6 & 17.9 \\
\hline
\end{tabular}

Table 3. Monthly average maximum and minimum temperature during crop seasons 2008-09 and 2009-10

\begin{tabular}{llllllll}
\hline & November & December & January & February & March & April & May \\
\hline \multicolumn{2}{l}{ Crop season $2008-09$} & & & & & & \\
\hline Max temp & 27.8 & 22.6 & 19 & 23.5 & 28.9 & 36.2 & 38.1 \\
Min Temp & 11.6 & 9.0 & 7.7 & 9.0 & 12.6 & 18.4 & 23.3 \\
\hline Crop season $2009-10$ & & & & & & \\
\hline Max temp & 26.6 & 21.7 & 16.0 & 22.9 & 30.8 & 39.5 & 39.4 \\
Min Temp & 11.1 & 6.4 & 6.7 & 8.8 & 14.6 & 20.2 & 24.3 \\
\hline
\end{tabular}

\subsection{Stress Indices}

The stress susceptibility and tolerance indices were calculated using following formulae:

Stress Susceptibility index $(\mathrm{SSI})=[1-(\mathrm{xs} / \mathrm{xp})] /[1-(\mathrm{Xs} / \mathrm{Xp})]$

Tolerance $(\mathrm{TOL})=\mathrm{xp}-\mathrm{xs}$

Mean Productivity $(\mathrm{MP})=(\mathrm{xp}+\mathrm{xs}) / 2$

Geometric Mean Productivity $($ GMP $)=\sqrt{ }(x p \times x s)$

Heat Tolerance Index $(\mathrm{HTI})=(\mathrm{xs} \times \mathrm{xp}) /(\mathrm{Xp})^{2}$

Where, $x$ s is the trait value (thousand grain weight) of the genotype under stress, $x p$ is the trait value of the genotype under non- stress conditions. Xs and Xp are mean values of the trait of all the genotypes under stress and non-stress conditions respectively.

The principal component analysis was used to explain all the data variables by minimum number of components. The biplot display of principal component analysis was used to identify suitable stress tolerant indices, stress tolerant genotypes with high thousand grain weight. Three dimensional plots among TGW(non-stress) (x-axis), TGW(stress) (y-axis) and STI (z-axis) were used to categorize genotypes into four groups; those with high TGW under both stress and non-stress environments, those having high TGW in non-stress environment only, those having high TGW in stressed environments only and those having low TGW in both environments.

\subsection{Statistical Analysis}

Analysis of variance, correlations, principal component analysis and biplot drawing, three-dimensional plots drawing were performed using CROPSTAT (IRRI), SAS (SAS Institute, 2009), XLSTAT (2012) software, respectively.

\section{Results and Discussion}

The average TGW pooled over two years was 43.4g under non-stress and $33.1 \mathrm{~g}$ under stress conditions. Under non-stress conditions, genotype S9 had highest TGW followed by genotypes S28, S51, S34, S37, S52 and S24. Similarly under stress conditions also, genotype S9 had highest TGW followed by genotypes S11, S44, S37, S71 and S36. The genotypes also differed significantly for stress indices STI, MP and GMP. Based on these indices, genotypes S9, S51, S44, S71, S37, S14, S57, S24 and S35 had higher values in first year and genotypes S9, S11, 
S52, S34, S35, S37, S46, S36 and S42 in second year. Genotypes S9, S35 and S37 had high values during both years.

\subsection{Correlation among Traits and Indices}

TGW under stress environment showed positive and significant correlation with that under non-stress environment. TGW under both environments had significant positive correlation with STI, GMP and MP and non-significant negative correlations with SSI and TOL during both years (Tables $4 \& 5$ ). These results are in conformity with those of Boussen et al. (2010) and Karimizadeh \& Mohammadi (2011) in durum wheat and Abdolshahia et al. (2012) and Anwar et al., (2011) in aestivum wheat for drought stress. Khodarahmpour et al. (2011) also concluded the same correlations in maize inbred and hybrids for heat stress.

Table 4. Correlation coefficients in TGW under stress \& non-stress conditions and stress indices in first year

\begin{tabular}{llllllll}
\hline Variables & TGW(NS) & TGW(S) & SSI & STI & MP & TOL & GMP \\
\hline TGW(TS) & 1.000 & & & & & & \\
TGW(LS) & $0.449^{*}$ & 1.000 & & & & & \\
SSI & $-0.390^{*}$ & $-0.526^{* *}$ & 1.000 & & & & \\
STI & $0.759^{* *}$ & $0.692^{* *}$ & $-0.862^{* *}$ & 1.000 & & & \\
MP & $0.769^{* *}$ & $0.864^{* *}$ & $-0.391^{* *}$ & $0.721^{* *}$ & 1.000 & & \\
TOL & -0.131 & $-0.520^{* *}$ & $0.952^{* *}$ & $-0.735^{* *}$ & -0.255 & 1.000 & \\
GMP & $0.696^{* *}$ & $0.473^{*}$ & $-0.911^{* *}$ & $0.953^{* *}$ & $0.507^{* *}$ & $-0.769^{* *}$ & 1.000 \\
\hline
\end{tabular}

Table 5. Correlation coefficients in TGW under stress \& non-stress conditions and stress indices in second year

\begin{tabular}{llllllll}
\hline Variables & TGW(NS) & TGW(S) & SSI & STI & MP & TOL & GMP \\
\hline TGW(TS) & 1.000 & & & & & & \\
TGW (LS) & $0.594^{* *}$ & 1.000 & & & & & \\
SSI & $0.684^{* *}$ & -0.118 & 1.000 & & & & \\
STI & $0.895^{* *}$ & $0.876^{* *}$ & 0.334 & 1.000 & & & \\
MP & $0.931^{* *}$ & $0.843^{* *}$ & $0.409^{*}$ & $0.990^{* *}$ & 1.000 & & \\
TOL & $0.707^{* *}$ & -0.143 & $0.952^{* *}$ & 0.338 & $0.413^{* *}$ & 1.000 & \\
GMP & $0.909^{* *}$ & $0.871^{* *}$ & 0.370 & $0.993^{* *}$ & $0.998^{* *}$ & 0.360 & 1.000 \\
\hline
\end{tabular}

Table 6. First two principal components for TGW under stress and non stress conditions and stress indices in 28 synthetic wheats in two years

\begin{tabular}{lrrrr}
\hline & \multicolumn{2}{c}{ 1st year } & \multicolumn{2}{c}{ 2nd year } \\
\hline \multicolumn{1}{c}{ Traits } & Component1 & Component2 & Component1 & Component2 \\
\hline TGW(TS) & 0.715 & 0.533 & 0.976 & -0.196 \\
TGW(LS) & 0.766 & 0.290 & 0.745 & 0.663 \\
SSI & -0.880 & 0.463 & 0.551 & -0.813 \\
STI & 0.989 & 0.001 & 0.967 & 0.240 \\
MP & 0.758 & 0.606 & 0.986 & 0.162 \\
TOL & -0.765 & 0.610 & 0.552 & -0.825 \\
GMP & 0.925 & -0.204 & 0.976 & 0.213 \\
Eigenvalue & 4.866 & 1.365 & 4.976 & 1.949 \\
Variability (\%) & 69.517 & 19.500 & 71.092 & 27.846 \\
Cumulative \% & 69.517 & 89.017 & 71.092 & 98.939 \\
\hline
\end{tabular}




\subsection{Principal Component Analysis and Biplot}

The first two factors in principal component analysis explained more than $89 \%$ variation in the data during first year and $98 \%$ in the second year (Table 6). The factor one explained $69.5 \%$ variation for TGW under non-stress and stress conditions and STI, MP and GMP in first year and 71.1\% in second year. The maximum contribution by individual variable for first factor was by STI followed by GMP in first year and by STI, GMP and MP in second year. Therefore it reflects high thousand grain weight and stress tolerance. The second component explained 19.5 and $27.9 \%$ variation and had coordination with stress susceptibility indices. The maximum contribution by individual variable for second factor was by TOL in first year and SSI and TOL in second year. Using principal components, biplot for genotypes and stress indices is drawn. The angles and directions between the attribute vectors illustrate the strength and the direction of correlation between any two attributes (Fernandez, 1992). Significant positive correlation was observed between STI \& GMP, STI \& TGW(S), TGW (NS) \& TGW(S) and TGW (NS) \& MP in first year (Figure 1) and STI \& GMP, STI \& MP, STI \& TGW (NS) and STI $\& \mathrm{TGW}(\mathrm{S})$ in second year (Figure 2). These observations are in conformity with correlation results. This indicates that STI, GMP and MP are the best selection criteria. These indices have been used by Fernandez (1992), Talebi et al. (2009), Nouri et al. (2010) and Mohammadi et al. (2011) also for stress tolerance.

\subsection{Three Dimensional Plots}

In order to identify tolerant and susceptible genotypes, three dimensional plots were drawn with TGW under two environments and STI (Figures $3 \& 4$ ). The plot was divided into four components using average thousand grain weight under stress and non-stress conditions. Genotypes S9, S44, S51, S71, S57, S24, S14 and S37 were in A group with high TGW in both environments in first year. Of these genotypes S51, S24 and S14 were placed in group B in second year i.e these genotypes had high TGW in non-stress environments during second year and genotype S71 in group C i.e. it had high TGW in stressed environments in second year. Genotypes S23, S49, S77, S27, S8 and S22 were placed in group D i.e these genotypes had low TGW in both environments in first year. All these genotypes except S27 had low TGW in second year also. Based on three dimensional plots for two years it is concluded that genotypes S9, S44, S24 and S37 had high TGW in both environments and high STI also whereas genotypes S23, S49, S77, S8 and S22 had low TGW and low STI.

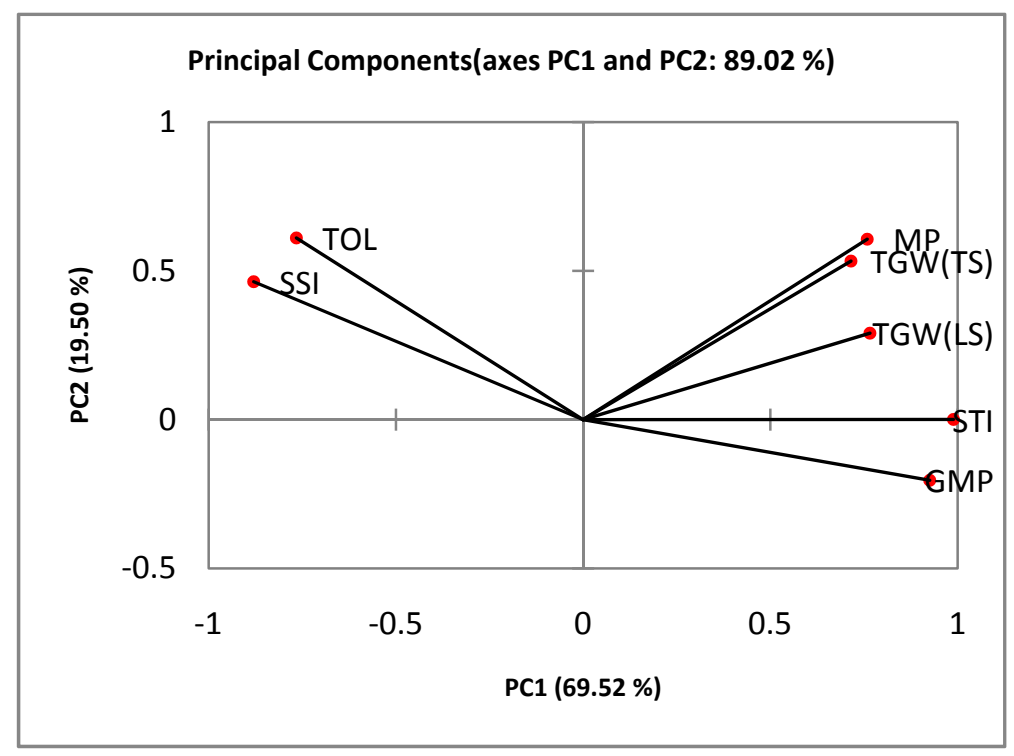

Figure 1. First and second principal components for stress indices in first year 


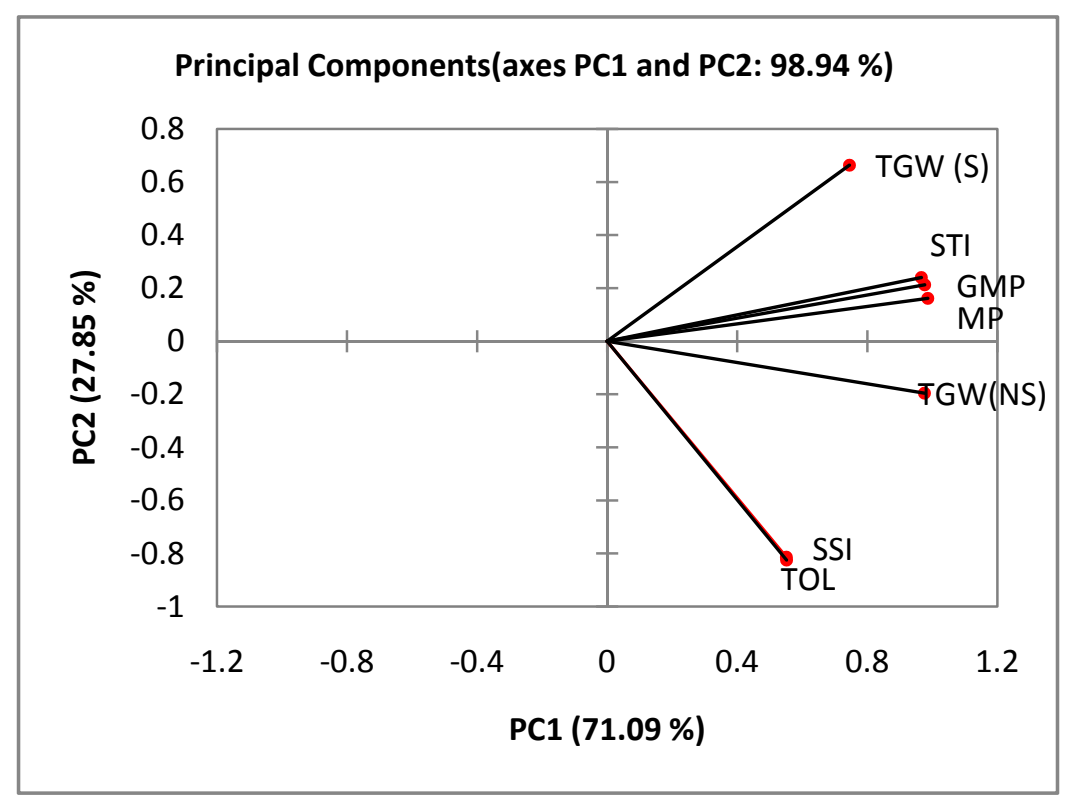

Figure 2. First and second principal components for stress indices in second year

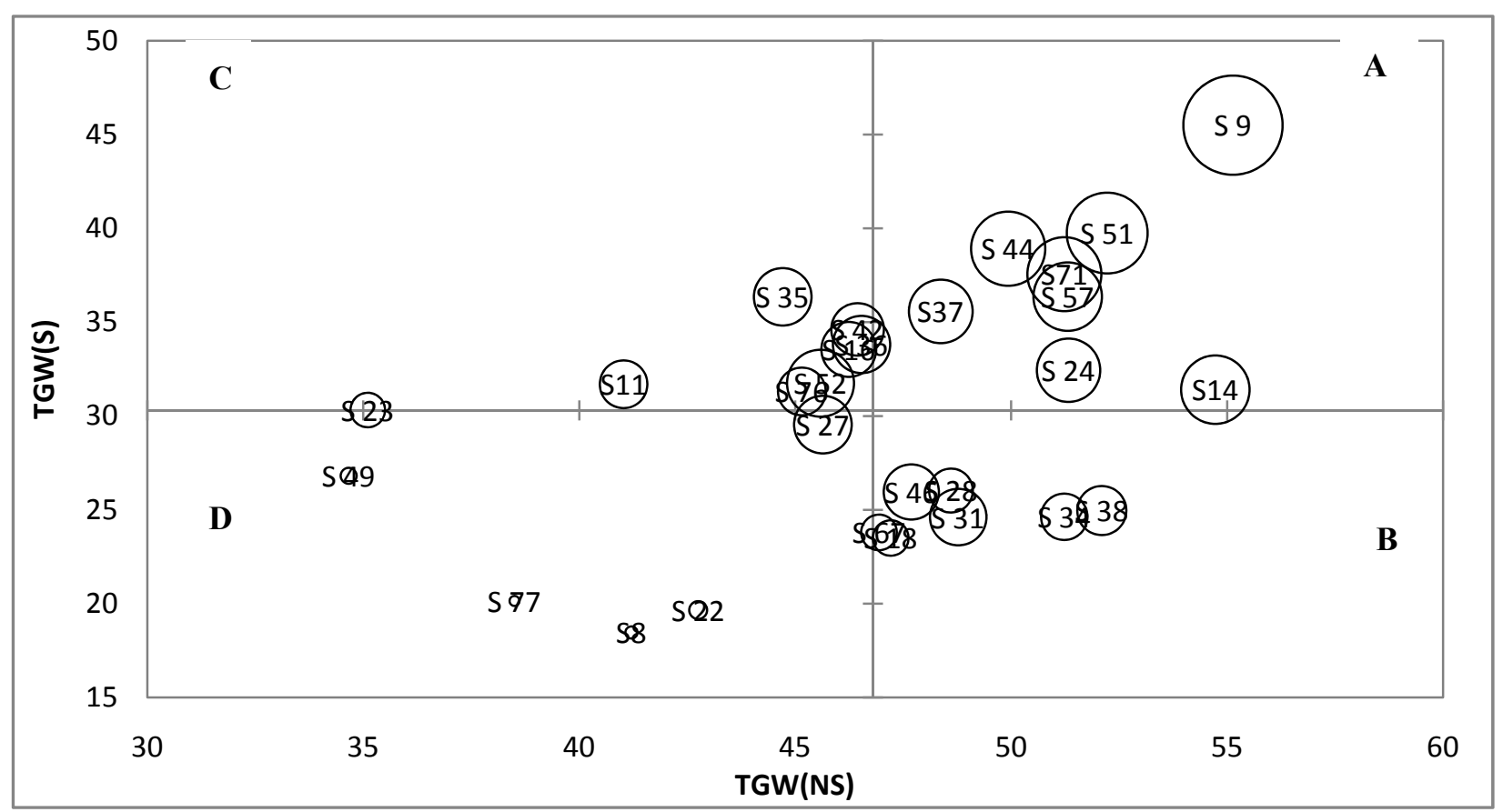

Figure 3. Three dimensional plot among TGW(NS), TGW(S) and STI in first year 


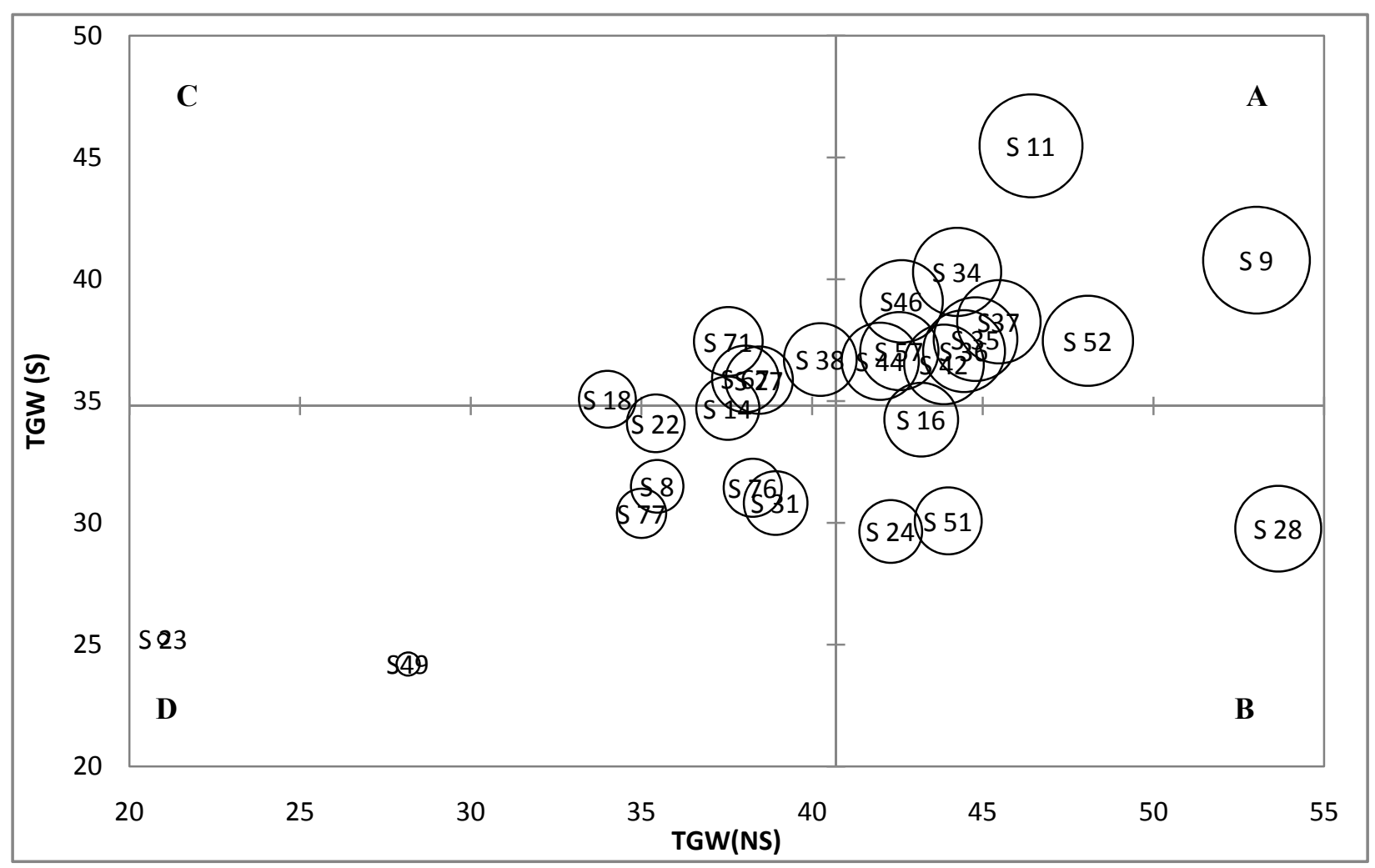

Figure 4. Three dimensional plot among TGW(NS), TGW(S) and STI in second year

\section{Conclusions}

Concerted efforts are being made to develop genotypes for stress prone environments particularly in view of predictions of global warming and climate change. There is need to identify genotypes that are good performing under both stress as well as non stress environments. The stress tolerance indices like STI, MP and GMP can be used as selection criteria to identify these genotypes. During present study, using these indices genotypes S9, S44, S24 and S37 were identified as heat tolerant genotypes and these can be recommended for use in breeding programs for stressed environments.

\section{References}

Abdolshahia, R., Safariana, A., Nazaria, M., Pourseyedib, S., \& Mohamadi-Nejad, G. (2012). Screening drought-tolerant genotypes in bread wheat (Triticum aestivum L.) using different multivariate methods. Archives of Agronomy and Soil Science, 1-20. http://dx.doi.org/10.1080/03650340.2012.667080

Anwar, J., Subhani, G. M., Hussain, M., Ahmad, J., Hussain, M., \& Munir, M. (2011). Drought tolerance indices and their correlation with yield in exotic wheat genotypes Pak. J. Bot., 43(3), 1527-1530. http://www.pakbs.org/pjbot/PDFs/43(3)/PJB43(3)1527.pdf

Boussen, H., Ben Salem, M., Slama, A., Mallek-Maalej, E., \& Rezgui, S. (2010). Evaluation of drought tolerance indices in durum wheat recombinant inbred lines Options Méditerranéennes, A no., 95, 79-83 http://ressources.ciheam.org/om/pdf/a95/00801329.pdf

Fernandez, C. G. J. (1992). Effective selection criteria for assessing plant stress tolerance. In C. G. Kuo, ed. Adaptation of Food Crops to Temperature and Water Stress (pp. 257-270), AVRDC, Shanhua, Taiwan.

Fischer, R. A., \& Maurer, R. (1978). Drought resistance in spring wheat cultivars. I. Grain yield responses. Australian Journal of Agricultural Research, 29, 897-912. http://dx.doi.org/10.1071/AR9780897

Hays, D., Mason, E., HwaDo, J., Menz, M., \& Reynolds, M. (2007). Expression of quantitative trait loci mapping heat tolerance during reproductive development in wheat (T. aestivum). In Buck, H. T., Nisi, J. E., Salomón, N. (eds), Wheat production in stressed environments (pp. 373-382). Springer, Netherlands, Amsterdam. http://dx.doi.org/10.1007/1-4020-5497-1_46 
Joshi, A. K., Chand, R., Arun, B., Singh, R. P., \& Ortiz Ferrara, G. (2007a). Breeding crops for reduced-tillage management in the intensive, rice-wheat systems of South Asia. Euphytica, 153, 135-151. http://dx.doi.org/10.1007/s10681-006-9249-6

Joshi, A. K., Mishra, B., Chatrath, R., Ortiz Ferrara, G., \& Singh, R. P. (2007b). Wheat improvement in India: Present status, emerging challenges and future prospects. Euphytica, 157, 431-446. http://dx.doi.org/10.1007/s10681-007-9385-7

Karimizadeh, R., \& Mohammadi, M. (2011). Association of canopy temperature depression with yield of durum wheat genotypes under supplementary irrigated and rainfed conditions. AJCS, 5(2), 138-146. http://www.cropj.com/karimizadeh_5_2_2011_138_146.pdf

Khodarahmpour, Z., Choukan, R., Bihamta, M. R., \& Hervan, E. M. (2011). Determination of the Best Heat Stress Tolerance Indices in Maize (Zea mays L.) Inbred Lines and Hybrids under Khuzestan Province Conditions J. Agr. Sci. Tech., 13, 111-121.

Mohammadi, M., Karimizadeh, R., \& Abdipour, M. (2011). Evaluation of drought tolerance in bread wheat genotypes under dryland and supplemental irrigation conditions AJCS, 5(4), 487-493. http://www.cropj.com/mohammadi_5_4_2011_487_493.pdf

Nouri, A., Etminan, A., Jaime, A., Teixeira, S., \& Mohammadi, R. (2011). Assessment of yield, yield-related traits and drought tolerance of durum wheat genotypes (Triticum turjidum var.durum Desf.). Aust J Crop Sci., 5, 8-16. http://www.cropj.com/nouri_5_1_2011_8_16.pdf

Reynolds, M. P, Nagarajan, S., Razzaque, M. A., \& Ageeb, O. A. A. (2001). Heat tolerance. In Reynolds MP, Ortiz-Monasterio JI, McNab A (eds.). Application of physiology in wheat breeding. Mexico, D. F.: CIMMYT. http://apps.cimmyt.org/research/wheat/map/research_results/wphysio/WPhysio.pdf

Rosielle, A. A., \& Hamblin, J. (1981). Theoretical aspects of selection for yield in stress and non-stress environments. Crop Sci., 21, 943-946. http://dx.doi.org/10.2135/cropsci1981.0011183X002100060033x

Talebi, R., Fayaz, F., \& Naji A. M. (2009). Effective selection criteria for assessing drought stress tolerance in durum wheat (Triticum wheat DESF.). Gen. Appl Plant Physio, 35, 64-74. www.bio21.bas.bg/ipp

Wardlaw, I. F., Dawson, I. A., \& Munibi, P. (1989). The tolerance of wheat to high temperatures during reproductive growth: II Grain development. Australian Journal of Agricultural Research, 40, 15-24. http://dx.doi.org/10.1071/AR9890015 